\title{
Young guns: an empirical study of persons who use a firearm in a suicide or a homicide
}

\author{
Susan B Sorenson, Richard A Berk
}

\begin{abstract}
Objectives-The purpose of this investigation was to identify population groups at highest risk of using a firearm in a fatal incident.

Setting-Los Angeles County (California, USA).

Methods-Data were gathered from vital statistics reports and law enforcement records on the characteristics of suicide victims $(n=4799)$ and homicide suspects ( $n=5369)$ from 1990 through 1994. Logistic regression was used to identify characteristics of the actor/perpetrator that were associated with firearm use.

Results-Persons less than 21 years old and males were more likely to use a firearm to kill themselves or someone else. Even when their other demographic attributes and characteristics of the incident itself were taken into consideration, persons under the age of 18 were substantially more likely than those 21 or more years old to use a firearm in the commission of a homicide (adjusted odds ratio $=$ 2.59). Asians were less likely than white people to use a firearm in the commission of a suicide, whereas black people, Hispanics, and Asians were more likely than whites to use a firearm in the commission of a homicide.

Conclusions-The US enacts and enforces some policies differentially by age. These data support the idea that such an approach may be warranted when addressing fatalities associated with the use of a firearm. Of particular interest, given minimum age requirements for firearm purchases, is the source of the weapons themselves.
\end{abstract}

(Injury Prevention 1999;5:280-283)

Keywords: ethnicity; firearms; homicide; suicide

University of California, Los Angeles: School of Public Health

S B Sorenson

Department of

Statistics

R A Berk

Correspondence to: Dr Susan B Sorenson, University of California Los Angeles, School of Public

Health, 10833 Le Conte Ave,

Los Angeles, CA

90095-1772, USA persons: the proportion of homicide deaths attributed to firearms among 15-34 year olds rose from $66.4 \%$ in $1985^{1}$ to $79.8 \%$ in $1997,{ }^{3}$ the most recent year for which final data are available. The proportion of suicide deaths of 15-34 year olds attributed to firearms re- mained stable during this same period $(57.3 \%$ in $1985^{1}$ and $56.8 \%$ in $1997^{3}$ ).

Preventing firearm related deaths is a substantial challenge. Most efforts have focused on the availability or accessibility of firearms. Whether the strategy is to restrict or to increase firearm availability and accessibility, ${ }^{4-7}$ an underlying goal is to equalize force in situations with the potential for interpersonal violence so as to reduce injury. Intervention points have focused primarily, although not solely, on points of purchase and regulating who is eligible to purchase and possess a firearm (for example, persons who have been convicted of a felony or adjudicated mentally are prohibited from purchasing a firearm), regulating who is able to carry a firearm (for example, concealed carry permits), and regulating the type and quantity of firearms that can be purchased and possessed (for example, assault weapons, limiting purchases to "one gun a month"). Such efforts address the general population despite evidence of disparate risk across population groups, for example, an epidemic of firearm homicide among youth ${ }^{1}$ and the growing use of firearms in suicide by elderly women. ${ }^{8}$

The purpose of this investigation was to examine demographic and situational correlates of fatal firearm use patterns across population groups in order to help identify appropriate intervention points and methods. Thus, rather than examine characteristics of the decedent, as is typical in health literature, we examined characteristics of persons who used the firearm, namely, the suicide victim and the homicide suspect ${ }^{\star}$. For suicides, we considered the role of gender, ethnicity, nativity and, especially, age. For homicides, we considered, in addition to these same demographic variables, whether the homicide was gang related, whether the victim and suspect knew each other, whether the suspect acted alone, and whether there was more than one victim. The distinction between biographical attributes and features of the homicide act itself is critical for intervention policy. If biography is, in an important sense, destiny, then interventions to reduce the role of firearms should focus primarily on certain population groups. However, if biography is just a proxy for high risk situations or behaviors, firearm injury prevention might concentrate on the context in which homicides are likely to occur. 


\section{Methods}

All persons who died of suicide $(n=4799)$ or who were homicide suspects $(n=5369)$ in Los Angeles County from 1990 through 1994 comprised the study population. Vital statistics data were obtained through the California Department of Health Services for information on the suicide victims. Law enforcement data (that is, police reports, district attorney files, and other such records) gathered for a special study by the Los Angeles Times was the source of data on the homicidest. Information on the general type of firearm, that is, a handgun versus a long gun, is not recorded in the vital statistics data; thus, comparisons herein are necessarily limited to the use of a firearm versus the use of another method.

The age, sex, ethnicity, and nativity frequencies of the suicide decedents and homicide suspects were examined for firearm use among all suicides and homicides. (Please note that birthplace data are available from the vital statistics data and citizenship data are available in the criminal justice data. Although not interchangeable, birthplace and citizenship are closely related, especially at young ages..$^{9}$ ) These same variables were then entered into a logistic regression to identify characteristics associated with the fatal use of a firearm in suicides and in homicides.

Additional factors (for example, whether the homicide was gang related) may account for any observed differences in demographic patterns of firearm homicides, so we conducted additional analyses on the homicide suspects to explore the impact of characteristics of the homicide incident itself on whether a firearm was used. Most homicide suspects $(93.1 \%)$ were suspected of killing one person; when suspected of killing multiple victims, characteristics of the first victim were recorded and analyzed.

It is important to underscore that rather than comparing the decedents in suicides and homicides, we were comparing characteristics of the actor/perpetrator, that is, the suicide decedent and the homicide suspect. No suspect was identified in a substantial proportion $(42.4 \%)$ of the homicides; somewhat surprisingly, this is the situation in many major metropolitan areas in the US. We have no basis on which to assert that the homicides in which there was a suspect represent those homicides in which there was not a suspect, but it may be important to note that the percentage of homicides due to firearms was roughly similar for the two groups during the study period $(53.5 \%$

†The Los Angeles Times published a series of Pulitzer prize nominated articles on criminal homicide in December 1996 The series examined whether race, media attention, and the social class of homicide victims and defendants had any bearing on the criminal justice outcome of the cases. It also studied the role of law enforcement agencies and court houses.

Data were gathered by interns trained by the second author and graduate student Cathie Lee. Any conflicts between documents were reconciled whenever possible. Information that seemed, on its face, to be in error was corrected by going back to original sources. Most of that legwork was done by Los to original sources. Most of that legwork was done by Los Angeles Times reporters, who were familiar with the "crime beat" and experienced with the documents in question. Apparent errors or inconsistencies that later turned up during analysis of the data were addressed in much the same way. Databases were constructed and in momputer analysis, and Sandra Poindexter, a data analyst, of the Lo Angeles Times. and $46.5 \%$, respectively). Moreover, we make the arguable assumption that the suspect identified in a homicide case actually was the perpetrator of the crime.

\section{Results}

Firearms were used in $52.4 \%$ of the suicides and $69.6 \%$ of the homicides in Los Angeles County during 1990 through 1994. As shown in table 1, firearm use in suicide was more common among men than women, was more common among the young and old compared with the middle aged, was less common among Asians compared with other ethnic groups, and differed little by nativity. The gender and birthplace patterns noted in suicides were also observed among homicides, but two additional demographic patterns are seen in the firearm use patterns in homicides: the youngest age group (15-24 year olds) was more likely than other age groups to use a firearm, and white people were less likely to use a firearm than persons of other ethnic groups.

For subsequent analyses, we grouped the ages to be consistent with the ages set in current federal firearms purchase policies (that is, $18+$ for long guns, $21+$ for handguns). Collapsing age categories in this manner resulted in the following: firearms were used in $67.3 \%$ of the suicides of persons under 18 years of age, $67.4 \%$ of the suicides of $18-20$ year olds, and $51.3 \%$ of the suicides of persons 21 or more years old; firearms were used by $85.3 \%$ of the homicide suspects who were less than 18 years old, $79.7 \%$ of the homicide suspects who were $18-20$ years old, and $63.9 \%$ of the homicide suspects who were 21 or more years old.

As shown in table 2, when the other listed demographic characteristics are taken into account, persons under the age of 21 years are substantially more likely to use a firearm in the

Table 1 Firearm use (percent) in intentional injury deaths, Los Angeles County, 1990 through 1994, by characteristics of the actor/perpetrator

\begin{tabular}{lll}
\hline & $\begin{array}{l}\text { Suicide victims } \\
\left(n=4595^{\star}\right)\end{array}$ & $\begin{array}{l}\text { Homicide suspects } \\
(n=4807 \dagger)\end{array}$ \\
\hline $\begin{array}{l}\text { Overall } \\
\text { Gender }\end{array}$ & 52.6 & 69.6 \\
$\quad$ Male & 77.3 & 71.4 \\
Female & 32.5 & 41.1 \\
Age (years) & & \\
0-4 & 0.0 & 0.0 \\
5-14 & 64.9 & 0.0 \\
15-24 & 63.3 & 81.3 \\
25-34 & 50.8 & 63.9 \\
35-44 & 41.8 & 54.3 \\
44-54 & 47.6 & 53.4 \\
55-64 & 58.0 & 61.9 \\
65+ & 57.5 & 0.0 \\
Ethnicity & & \\
White & 52.0 & 46.2 \\
Hispanic & 56.0 & 71.5 \\
Black & 58.4 & 73.2 \\
Asian/other & 43.1 & 68.4 \\
Nativity & & \\
US born & 53.3 & $72.2 \ddagger$ \\
Foreign born & 51.0 & $72.2 \ddagger$ \\
\hline
\end{tabular}

Total number is $4799 ; 204$ cases were missing data on one or more variables.

†Total number is $5369 ; 562$ cases were missing data on on or more variables.

$\ddagger$ Total number is $4153 ; 654$ of the 4807 cases were missing nativity data. Please note that the percentages of the other demographic variables remain relatively stable whether or not nativity is included. 
Table 2 Likelihood of using a firearm by characteristics of the actor/perpetrator, Los Angeles County, 1990 through 1994

\begin{tabular}{|c|c|c|}
\hline & $\begin{array}{l}\text { Suicides: } \\
\text { adjusted odds ratio } \\
\text { (95\% confidence } \\
\text { interval) }\end{array}$ & $\begin{array}{l}\text { Homicides: } \\
\text { adjusted odds ratio } \\
\text { ( } 95 \% \text { confidence } \\
\text { interval) }\end{array}$ \\
\hline \multicolumn{3}{|l|}{ Gender } \\
\hline Male ( $v$ female) & $2.93(2.52$ to 3.39$)$ & 3.45 (2.63 to 4.53$)$ \\
\hline \multicolumn{3}{|l|}{ Age (years) } \\
\hline$<18(v 21+)$ & $2.00(1.42$ to 2.83$)$ & $3.68(2.53$ to 5.36$)$ \\
\hline $18-20$ & $1.93(1.44$ to 2.60$)$ & $2.42(2.02$ to 2.91$)$ \\
\hline \multicolumn{3}{|l|}{ Ethnicity } \\
\hline Hispanic ( $v$ white) & $1.04(0.87$ to 1.23$)$ & 2.09 (1.64 to 2.66$)$ \\
\hline Black & $1.20(0.96$ to 1.51$)$ & $3.00(2.38$ to 3.79$)$ \\
\hline Asian/other & $0.74(0.57$ to 0.95$)$ & $1.65(1.10$ to 2.47$)$ \\
\hline \multicolumn{3}{|l|}{ Nativity } \\
\hline US born ( $v$ foreign born) & $1.09(0.92$ to 1.27$)$ & $0.97(0.82$ to 1.15$)$ \\
\hline
\end{tabular}

Note: The adjusted odds ratios presented here statistically adjust for the other variables listed in the table. homicides, and $71.7 \%$ of the time when there was a sole victim compared with $87.0 \%$ of the time when there were two victims, and $89.7 \%$ of the time when there were three or more victims. Even when taking into consideration the characteristics of the homicide suspect and the homicide incident itself (table 3), being less than 21 years old, being male, and being Hispanic or black were positively associated with firearm use. Firearms were more likely to be used in stranger, gang, and multiple victim homicides. Firearm use was less likely if the suspect was US born or acted alone.

\section{Discussion}

Firearm injuries have been likened to cholera, smallpox, and other infectious diseases that public health has addressed and sometimes eradicated. However, in the prevention of firearm injuries, public health is struggling to eliminate the outcome (that is, the injury) without necessarily eradicating the vector/ vehicle (that is, the firearm). In lieu of an agreed upon comprehensive strategy (for example, to arm all residents, to ban the possession of all handguns), it may be helpful to identify strategies that may work with specific population groups.

In the US there is general sentiment that, without compelling justification to the contrary, laws are not to be developed or enforced differentially according to, among other things, persons' ethnicity, gender, and socioeconomic statusł. We routinely do, however, allow and generally support policies that take age into account. Lower limits have been established at which ages persons may, for example, legally drink alcohol, engage in sexual intercourse, obtain a license to drive a motor vehicle, and vote. These ages have varied across jurisdictions and across time (for example, legal drinking age was decreased from 21 to 18 years by many states in the 1970 s and reinstated to 21 years by all in the late 1970s and 1980s).

Gun ownership generally begins at young ages; nearly half of the firearm owners in a recent national survey by the Police Foundation reported that they owned a gun before the age of $21{ }^{10}$ Although the federal minimum age at which to buy a firearm from a dealer is 18 years for long guns and 21 years for handguns, ${ }^{11}$ a number of jurisdictions allow juveniles to possess a firearm under certain circumstances. For example, in California the sale of any firearm to a minor is unlawful (California Penal Code 12551, 12100), but minors are allowed to possess a handgun and ammunition with the written permission of his or her parent or guardian or if he or she is accompanied by the parent or guardian while in possession of the handgun (California Penal Code 12101).

Findings from this investigation indicate that, even if other violence prevention strategies (for example, gang violence reduc-

$\ddagger$ Policies with compelling justification to the contrary would include those designed to remediate past inequities (for example, affirmative action programs) or to ameliorate current example, affirmative action programs) or to ameliorate current
circumstances (for example, food stamps and other nutritional programs for the poor).
progrances (for examplo liusted odds ratios presented here statistically $\uparrow$ Note: The adjusted odds ratios presented
adjust for the other variables listed in the table. 
tion) are successful, persons under 21 years of age still would be more likely than their older counterparts to use a firearm in the commission of a homicide. Biography is not destiny, but it seems to have an independent role beyond the situational factors we were able to evaluate. Moreover, the current focus on violent crimes, including firearm involved crimes, committed by juveniles may obscure the observation that juveniles also are more likely than older persons to use a firearm in the commission of a suicide. These findings lend support to the differential enforcement by age of policies related to firearm ownership and possession.

\section{IMPLICATIONS}

Although characteristics of youth (for example, impulsiveness) may be related to homicide and suicide incidents, public health generally has not found it productive to focus on the population group itself as the problem. ${ }^{12}$ Criminologists and policy specialists join the public health emphasis on the weapon itself. ${ }^{13}{ }^{14}$ We focus herein on one aspect of the issue, that is, the source of the weapons.

Given that federal law prohibits firearm purchase by minors, the source of the weapons themselves is of primary importance in preventing firearm suicide and homicide by juveniles. Some research has found that the parental home is the most common source of firearms that adolescents and young adults use to kill themselves. ${ }^{15}$ Family and friends and "off the street" are the two most common sources of guns for inner city high school students. ${ }^{14}$ Thus, the issue of the lethal use of firearms by persons under the age of 21 years may be related to general firearm availability and accessibility.

Many firearms used by street criminals are believed to be stolen or transferred between private parties. ${ }^{16}{ }^{17}$ Recent research, however, suggests that a focus on the licensed firearm industry, which constitutes the primary gun market, ${ }^{18}$ also may be productive. Retail sources, that is, licensed dealers who divert sizeable quantities of firearms to unlicensed street vendors and directly to end users, appear to be an important source of firearms for criminal offenders. ${ }^{19}$ It appears that only a few corrupt dealers and unlicensed vendors are responsible for a substantial proportion of recovered guns. ${ }^{19}$

Retail firearm dealers are not to sell guns to underage persons much like bartenders and retail outlets selling alcohol are not to sell alcohol to minors. As with retail alcohol outlets, mechanisms by which to monitor underage sales, straw purchasers, and so forth may need to be employed to monitor the business practices of retail firearm outlets. Unfortunately, although oversight authority is established by federal laws and regulations, dealer inspections are relatively rare. Programs such as the Youth Crime Gun Interdiction Initiative, which is active in a number of US cities, are designed to identify dealers who serve as a source of firearms for youth. Established procedures used to monitor drug trafficking also may be of use to better understand the illegal trafficking of firearms to minors.

\section{Implications for prevention}

The central finding of this investigation is that, even when taking into account several key characteristics of the shooter and the nature of the incident itself (for example, whether a homicide was gang related), persons less than 21 years of age were more likely than their older counterparts to use a firearm in the commission of a suicide or homicide. This relationship was even stronger for those under 18 years old. One primary implication of these findings is that even if one could intervene to alter the circumstances in which young people commit homicides and suicides, age would continue to be a critical factor. Given that one cannot change age, if the goal is to reduce firearm homicides and suicides among young people, reducing their access to firearms remains an important strategy.

The authors thank the California Wellness Foundation for funding this research and the Los Angeles Times and the California Department of Health Services for making the data available. These findings were presented at the November 1999 convention of the American Public Health Association.

1 Fingerhut LA, Ingram DD, Feldman JJ. Homicide rates among US teenagers and young adults. $7 A M A$ 1998;280:423-7.

2 US Department of Justice. Crime in the United States 1995. Uniform Crime Reports. Washington, DC: US Department of Justice, 1996: chart 2.6.

3 Hoyert DL, Kochanek KD, Murphy SL. Deaths: final data for 1997. National vital statistics reports. Vol 47, No 19 . Hyattsville, MD: National Center for Health Statistics, 1999: table 19.

4 Hemenway D, Solnick SJ, Azrael DR. Firearm training and storage. $\mathcal{F} A M A$ 1995;273:46-50.

5 Kellermann AL, Rivara FP, Rushforth NB, et al. Gun ownership as a risk factor for homicide in the home. N Engl f ership as a risk factor for

6 Kleck G, Gertz M. Armed resistance to crime: the prevalence and nature of self-defense with a gun. Fournal of Criminal Law and Criminology 1995;86:150-81.

7 Lott JR Jr, Mustard DB. Crime, deterrence, and right-tocarry concealed handguns. Fournal of Legal Studies 1997;26 $1-68$

8 Adamek ME, Kaplan MS. The growing use of firearms by suicidal older women, 1979-1992: a research note. Suicide and Life-Threatening Behavior 1996;26:71-8.

9 Allen JP, Turner E. Spatial patterns of immigrant assimilation. Professional Geographer 1996;48:140-55.

10 Cook PJ, Ludwig J. Guns in America. Washington, DC: Police Foundation, 1996.

11 Gun Control Act of 1968. Public Law No 90-618, 82 Stat 1213.

12 Males MA. The scapegoat generation. Monroe, MA: Common Courage Press, 1996

13 Blumstein A, Cork D. Linking gun availability to youth gun violence. Law and Contemporary Problems 1996;59:5-24.

14 Cook PJ, Laub JH. The unprecedented epidemic in youth violence. In: Tonry $\mathrm{M}$, Moore $\mathrm{MH}$, eds. Youth violence. Chicago: University of Chicago Press, 1998: 101-38.

15 Brent DA, Perper JA. Research in adolescent suicide: implications for training, service delivery, and public policy. Suicide and Life-Threatening Behavior 1995;25:222-30.

16 Decker S, Pennell S. Arrestees and guns: monitoring the illegal firearms market. Washington, DC: National Institute of Justice, 1995.

17 Sheley J, Wright J. Gun acquisition and possession in selected juvenile samples. Washington, DC: National Institute of Jusjuvenile sample

18 Cook PJ, Molliconi S, Cole T. Regulating gun markets. fournal of Criminal Law and Criminology 1995;86:59-92.

19 Wachtel J. Sources of crime guns in Los Angeles, California Policing: An International fournal of Police Strategies and Management 1998;21:220-39. 